\title{
The Investigation of benthic macroinvertebrates in
}

\section{Baiyangdian Lake}

\section{Hong-wei WANG ${ }^{1,2, \text { a }}$, Li-kun YANG ${ }^{1, b}$, Chun-long ZHAO $^{3, c^{*}}$, Zhao-jin CUI ${ }^{3, d}$,}

\author{
Hai-tao ZHAO ${ }^{3, \text { e }}$, Wei-feng TANG ${ }^{1, \mathrm{f}}$, Qian-qian LIU $^{1, \mathrm{~g}}$ \\ 1. The Key Laboratory of Zoological Systematics and Application, College of Life Science, Hebei \\ University, Baoding, P.R. China \\ 2. South China Institute of Environmental Sciences, MEP, Guangzhou, P.R .China \\ 3. Hebei Ocean \& Fishery Sciences Research Institute, Qinhuangdao, P.R .China \\ awwanghw6688@gmail.com, bhwoods@126.com, 'bio2008@126.com (Communication author) , \\ d906472733@qq.com, eok200090@hotmail.com, 'whw66@hub.edu.cn, 985900389@qq.com
}

Key words: Baiyangdian Lake; Zoobenthos; Diversity

Abstract: The Zoobenthos in Baiyangdian Lake in Hebei province of China were investigated during August to October 2014, including the community structure and diversity. Total of 23 zoobenthic species were collected at 9 sampling sites, including 17 species of mollusca, 2 species of annelida and 4 species of aquatic insects, accounted for $73.91 \%, 8.70 \%, 17.39 \%$ respectively. The research would reflect the macrobenthos biomass in Baiyangdian Lake, then providing certain theoretical basis for ecological restoration in Baiyangdian Lake.

Baiyangdian Lake is the largest wetland in the Haihe river plain, located in the central part of Hebei Province. It is famous for large areas of reed marshes and contiguous acres of lotus Lake, known as the Pearl of North China. Baiyangdian Lake plays an important role in maintaining the ecological system of wetland, regulating climate of Hebei plain and the Beijing Tianjin region, meliorating temperature and humidity conditions, increasing groundwater supply, maintaining the biodiversity and the source of rare species.

\section{Materials and Methods}

Considering several aspects such as the water entrance regions of polluted river, fish culture regions, livestocks and poultries cultivating regions, hydrostatic accumulation regions, representative lake, country living area and suburban easily polluted area, Setting 9 sample sites according to the area, morphology, ecological environment of the lake.

Environment of the sampling sites:

Nanliuzhaung(sewage river entrance), Yuanyangdao(the water entrance regions of polluted river), Shaochedian (hydrostatic accumulation regions), Wangjiazhai( Village livestocks and poultries cultivating regions), Zaolinzhuang (hydrostatic accumulation regions), Guangdian (half fish culture regions), Quantou (half fish culture regions), Caiputai (natural region), Duancun

(fish culture regions)。 
Using 1/16 $\mathrm{m}^{2}$ modified Peterson borrow devices to collect benthic macroinvertebrate. Take secondary sludge samples from each sampling stations, Use two screens to screen sludge samples, diameter is $1.00 \mathrm{~mm}, 0.5 \mathrm{~mm}$. Samples of the selected fixed with $75 \%$ ethanol solution, and then put it in the sampling bottle, labeled. The samples were analyzed for classification and identification by qualitative and quantitative results after took back to the lab.

\section{Results}

The list of the benthic macroinvertebrate in Baiyangdian Lake in Tab. 1

Tab. 1 The list of benthic macroinvertebrates in Baiyangdian Lake

(Hebei Province, China)

\begin{tabular}{l}
\hline \\
\multicolumn{1}{c}{ Species } \\
\hline Mollusca \\
Cipangopaludina chinensis(Gray) \\
C.cathayensis(Heude) \\
C.ampulliformis \\
Bellamya purificata(Heuda) \\
B.limnophila(Mabille) \\
B.Puadrata(Benson) \\
Radix swinhoei(H.Adams) \\
Anodonta woodiana woodiana $($ Lea) \\
Parafossarulus eximius (Frauenfeld) \\
Semisulcospira cancellata(Benson) \\
Ampullaria gigas Spix \\
Gyraulus convexiusculus(Hutton) \\
Hippeutis Humbilicalis(Benson) \\
Hippeutis cantori(Benson) \\
Lymnaea stagnalis $($ Linnaeus) \\
Physa foncinalis (Linnaeus) \\
Corbicula fluminea (Müller) \\
Annelida \\
Limnodrilus hoffmeisteri \\
erpobodella octoaclata Linne \\
Insect \\
Chironomus grplumosus Linn \\
Donacia provosti Fairmaire \\
Chironomus grplumosus Linn \\
Zygoptera sp. \\
\hline
\end{tabular}

Total of 23 zoobenthic species were achieved in the survey, including 17 species of mollusca, 2 species of annelida and 4 species of aquatic insects.

\section{Discussion}

According to the data, biological resources were rich in Baiyangdian Lake before 1984; freshwater algae plant was up to 9 phyla, 11 classes, 26 orders, 55 families, 142 genera, 406 species, and 27 varieties. Higher plants of aquatic vegetation have 47 species, belonging to 2 phyla, 21 families, and 33 genera. Zooplankton have protozoan 13 genera, rotifer 21 genera, cladocera 7 genera, copepod 8 species. And there are 38 species of benthos. Fish resources were also rich in Baiyangdian, total of 54 species, carp, snakehead fish and pelteobagrus fulvidraco play an important 
role. There were 192 species of birds, among them, birds which breeding in Baiyangdian have 97 species. However, survey during 1992 shows there are only 52 species. Fish was reduced to 11 families ,18 species in 2000. Even Only 23 species zoobenthic were found in this experiment. The shortage of water in the recent 20 years have caused the decrease of water into Baiyangdian Lake, increasingly serious water pollution, sediment deposition and the decrease of the area of the Lake, Which have a harmful effect on regional ecological environment. As the result of drought occurred frequently, ecological environment in Baiyangdian Lake take a turn for the worse, while wild animal and plant resources have been seriously damaged.

With the strongthening management by governments and self-repairing of ecosystems in Baiyangdian, now the analysis of collecting samples showed that chironomid larvae and annelids oligochaetes coexist, especially the predominance of chironomid larvae, which fully shows that the water quality of Baiyangdian Lake is significantly improved.

\section{Acknowledgements}

We wish to thank Prof. Marc Van den Heede, Dr. Pieter boets and Prof. Tianci Lee for editing this manuscript. We are grateful for the constructive comments of the reviewers. This research was supported by NSFC U1133005; Subject of the strong characteristic Biology in Hebei Province; The natural science foundation of Hebei Province (D2013201105); The Education Department of Hebei province key project (2013-77) ; Start project for returned overseas researchers of Hebei Province (2013); The Project-sponsored by SRF for ROCS， SEM(2014); Hydrobiology key discipline in Hebei province; Hebei Characteristics of Seafood Innovation Team of Modern Agro-industry Technology Research System; Projects of coastal habitat restoration in Qinhuangdao (Provincial Science and Technology Department, No. 15273303D) ; Hebei Provincial Key Laboratory of operating subsidy (item number: 14967611D); Funded by Hebei Province project for cultivating national key disciplines in biology; Funded by Heibei Province construction project in Strong and characteristic disciplines of biology.

\section{Reference:}

[1] Matteo C. Ichino, Malcolm R. Clark, Jeffrey C. Drazen, Alan Jamieson, Daniel O.B. Jones, Adrian P. Martin, Ashley A. Rowden, Timothy M. Shank, Paul H. Yancey, Henry A. Ruhl. The distribution of benthic biomass in hadal trenches: A modelling approach to investigate the effect of vertical and lateral organic matter transport to the seafloor. Deep Sea Research Part I: Oceanographic Research Papers, 2015, 100, 21-33.

[2] Henry Joutsijoki, Kristian Meissner, Moncef Gabbouj, Serkan Kiranyaz, Jenni Raitoharju, Johanna Ärje, Salme Kärkkäinen, Ville Tirronen, Tuomas Turpeinen, Martti Juhola .Evaluating the performance of artificial neural networks for the classification of freshwater benthic macroinvertebrates.Ecological Informatics, 2014, 20, 1-12.

[3] Cristina Gonzalo, Julio A. Camargo. The impact of an industrial effluent on the water quality, submersed macrophytes and benthic macroinvertebrates in a dammed river of Central Spain. Chemosphere, 2013, 93 (6): 1117- 1124. 